\title{
Núcleo dramático e senso comum: uma leitura de Café, de Mário de Andrade
}

\author{
Ivan Moura Silva ${ }^{1}$
}

Resumo: O presente trabalho analisará o romance Café (2015), de Mário de Andrade, sob as perspectivas formal e ideológica. No primeiro caso, será analisado o núcleo dramático que se desenvolve no capítulo As duas irmãs, considerando que esse núcleo se insere num "intervalo dramático". Isso ocorre devido ao fato de que a trama principal do romance é interrompida para que o núcleo dramático possa se desenvolver. Assim, Café inclui em sua estrutura características dos gêneros romance e drama, o que evidencia a abrangência permitida pela literatura. Já a análise ideológica mostrará o modo como a imprensa contribui para a difusão do senso comum, de modo a preencher a vida cotidiana dos personagens em torno de uma ideologia dominante. Essa ideologia se faz notar pelo comportamento cada vez mais burguês a que a família se submete com a vida na cidade, influenciada particularmente pela leitura de jornais e folhetins.

Palavras-Chave: Mário de Andrade. Núcleo dramático. Senso comum. Ideologia.

\section{Núcleo dramático e comicidade}

No fim da de década de 1920, Mário de Andrade inicia um grande romance, Café (2015), que teria cinco capítulos e oitocentas páginas cheias de psicologia e intensa vida. Mas o romance ficou inacabado, com apenas dois capítulos. Não foi a morte do autor que impediu o romance de se concretizar, pois ele ainda teria um período de mais de quinze anos de vida após ter iniciado o romance, tempo suficiente para concluí-lo. Desde o início da escrita, a dificuldade acompanhava o autor. Em carta à Manuel Bandeira, o autor afirma sobre Café: "Sinto que é superior às minhas forças e tenho mais ou menos a convicção de que vou ratar (...) Mas não é por isso que vou parar o livro não. Quero ver como que vou ratar e sempre, você entende, fica a esperancinha de ganhar a partida" (ANDRADE, 2015). Grande parte da dificuldade do autor se dá pela própria forma que ele propôs ao romance, com elementos que variam do dramático ao cômico, do popular ao erudito. Esse último aspecto se percebe claramente pelo fato de 0 personagem central, Chico Antônio, ser um cantador de cocos nordestino e a ideia da obra ter se tornado posteriormente uma ópera. Mesmo o romance foi projetado para abranger aspectos teatrais, o que se percebe na comparação dos

\footnotetext{
${ }^{1}$ Mestrando em literatura e crítica literária pela PUC-SP. Bolsista CAPES. Email: Ivan_moura09@hotmail.com
}

Revista de Letras JUÇARA, Caxias - Maranhão, v. 01, n. 01, p. 24 - 36, Jul. 2017. 
dois capítulos, que alternam entre a busca de Chico Antônio, no primeiro, e o drama que se estabelece na família paulista, no segundo.

No entanto, é no que se refere ao dramático e ao cômico que vamos discorrer nesse artigo. $O$ dramático é percebido no segundo capítulo, intitulado $A s$ duas irmãs, que narra o cotidiano de uma família paulista que enriqueceu com as plantações de café e decide se mudar da fazenda para a cidade grande. No entanto, o que chamamos de dramático é mais algumas características próprias do drama do que uma elevação em busca da essencialidade. Para Lukács (2009, p. 53), "o poder sintético da esfera da essência condensa-se na esfera construtiva do problema dramático: aquilo que é definido como necessário pelo problema, seja alma ou acontecimento, ganha existência por suas relações com o centro". Essa estrutura sintética pode ser encontrada no segundo capítulo, que rompe com a busca de Chico Antônio, narrada no primeiro capítulo. Na verdade, não há propriamente um rompimento, mas um intervalo dramático que faz o personagem ficar oculto por um instante, tanto é que o segundo capítulo se inicia com a chegada dele na fazenda e termina com a retomada do enfoque nesse personagem, ainda que brevemente. Não se sabe qual destino teria a família paulista no restante do romance, mas certamente Chico Antônio teria seu papel em todos os capítulos, o que confirma o enfoque principal na busca desse personagem, embora nem ele mesmo soubesse o que buscava.

$\mathrm{Na}$ narrativa desse capítulo, portanto, não há uma totalidade, mas uma unidade que se estabelece dentro dos limites do problema dramático. Mas é aqui que o cômico se revela, pois as relações que se estabelecem entre os personagens são de tal ordem que a essencialidade parece se projetar não numa elevação, mas num rebaixamento. Lukács (2009, p. 53), no que se refere ao problema dramático, afirma:

O problema aqui é inexprimível porque é a ideia do todo, porque apenas a consonância de todas as vozes é capaz de realçar a riqueza de conteúdo nele oculta. Para a vida, contudo, o problema é uma abstração; a relação entre um personagem e um problema nunca é capaz de assimilar em si toda a plenitude de sua vida, e todo acontecimento da esfera vital tem de proceder alegoricamente no tocante ao problema.

É justamente a consonância das vozes que apontam para o problema na narrativa do segundo capítulo de Café. O drama se desenvolve em torno das Revista de Letras JUÇARA, Caxias - Maranhão, v. 01, n. 01, p. 24 - 36, Jul. 2017. 
duas irmãs, Clara e Vivi, que têm características opostas. Enquanto Clara agia com mais naturalidade, com menos máscaras, o que a fez não se adaptar completamente à vida na cidade, Vivi adaptou-se perfeitamente não por ser espontânea ou natural, mas por encontrar na cidade os vícios que seu caráter pedia. As duas irmãs se casam com homens cujos temperamentos se parecem com os delas próprias. Fernando, marido de Clara, é simples e religioso, enquanto Celeu, marido de Vivi, tem ambições que se satisfazem com a ajuda de sua natureza corrupta. Completam a família Quinzinho, o pai das duas irmãs, e sua esposa Dona Eulália, a coitada, que é a única que se sacrifica pelo bem de todos.

O capítulo se desenvolve com a análise psicológica dos personagens que agem conforme os impulsos que são movidos por motivações que não chegam à consciência, mas que são substituídas por falsas motivações. Percebe-se claramente a influência da psicanálise na construção psicológica dos personagens. Mas as motivações reais dos personagens são de tal ordem que chega mesmo a haver um infantilismo na disputa das duas irmãs, o que vai criando uma atmosfera tanto mais cômica na medida em que o problema dramático vai se mostrando cada vez mais superficial. Um exemplo desse processo é o trecho que descreve a ida da família ao cinema. Fernando comprara de antemão uns ingressos para Quinzinho não ter que pagar, mas, para não exceder o número de pessoas na parte da frente do camarote, alguém teria que sentar mais para trás. No caso, ficava "visível que a entrada excedente do número de pessoas do camarote, era a entrada de Celeu" (ANDRDADE, 2015, p. 181). Com isso, Celeu, apesar de emburrado, dizia: "Não senhor! o camarote é seu! Nós ficamos atrás, Vivi" (ANDRADE, 2015, p. 181). No Entanto, ao chegar em casa, Celeu e Vivi conversavam e reclamavam que não tinham visto nada. $O$ casal não se dirigia aos outros, mas "tinham ambos um jeito habilíssimo de maltratar os outros sem queixa". Certa vez Clara se manifestou sobre as reclamações do casal, o que ocasionou uma briga:

As duas irmãs tiveram então uma discussão feia, porque Clara, se sentindo com razão e sem... razão, perdera a tramontana desesperada com o caso e com tudo o que se ajuntara. Celeu defendeu a mulher, enquanto Fernando ia embora pro quarto numa aparência de deselegância que ainda mais desesperou Clara. Mas de repente, quando 
Vivi percebeu que Celeu a defendia, disparou num choro gritado que parecia que estavam enfiando punhais nela, uma coisa intempestiva que assustou os pais e a criadagem veio assuntar (ANDRADE, 2015, 181).

O exemplo permite identificar o jogo de aparências que se estabelece entre os personagens. Celeu, mais bem sucedido financeiramente que Fernando, se incomodava com o fato deste último comprar as entradas para o camarote e, principalmente, com o fato de ser ele, Celeu, quem deveria ficar no pior lugar do camarote. Na verdade, ninguém dizia claramente que era ele que deveria ficar no pior lugar, mas havia uma intuição que fazia com que todos percebessem. Num primeiro momento, pode-se dizer que isso tem relação com a hierarquia familiar, isto é, os sogros de Fernando deveriam ter certa prioridade natural pela posição que eles ocupavam na família. No entanto, não se trata apenas disso, porque Celeu, apesar de também intuir essa hierarquia, aumentava o drama da situação ao dizer energicamente que ficaria na parte de trás do camarote. É como se ele quisesse acentuar a situação para mostrar que, apesar de mais bem sucedido, ele não se importava em ficar com o pior lugar ou para mostrar que ele se incomodava com o fato de Fernando pagar as entradas. Provavelmente o próprio Celeu não saberia qual a real motivação dessa atitude. Pode ser mesmo que as duas opções façam sentido, mas elas estão em níveis diferentes. Por um lado há uma aparência de humildade que Celeu quer transmitir; por outro, há a motivação real que é o incômodo que ele sentia com o fato de Fernando, que não era bem sucedido como ele, pagar as entradas.

Seja como for, o drama parece aumentar em intensidade conforme cada personagem sinta seu ego ameaçado. As reclamações de Celeu e Vivi sem se dirigir diretamente ao demais era 0 modo como as insatisfações do casal poderiam se manifestar sem que o ego do casal ficasse ameaçado. Mas quando Clara enfim se manifesta sobre as reclamações do casal (porque isso atingia diretamente seu próprio ego) acontece uma discussão acalorada envolvendo a todos, porque então o ego do casal volta a ficar ameaçado. Ocorre que é nesses momentos de maior intensidade dramática que o cômico mais aparece, pois aí o temperamento de cada um precisa se adaptar ao momento dramático e os impulsos, cada vez mais difíceis de serem controlados, ameaçam o ego e colocam à prova $\mathrm{o}$ jogo de aparências. $O$ que os personagens precisam é 
equilibrar esse jogo para que o enfoque não permaneça em si mesmo enquanto portador do problema dramático. Para isso devem limitar as ações de acordo com o momento, mas um acontecimento novo, e a consequente necessidade de defesa, permite aumentar a intensidade das ações até o ponto em que a bola seja lançada novamente ao oponente.

Mas essa sucessão de acontecimentos chega num ponto em que se perde o controle das ações e a confusão passa a ser geral. Clara chega a se sentir ao mesmo tempo com e sem razão. Nesses momentos, é preciso se agarrar a qualquer coisa que possa restabelecer o equilíbrio. É aí que o papel do cônjuge se faz notar não como companheiro, mas como aliado momentâneo. Clara, ao ver que Fernando se retirava para o quarto, se desespera ainda mais. Vivi, ao perceber que Celeu a defendia, disparou num choro gritado. Essa reação das irmãs diante das atitudes dos maridos revela também o efeito dramático sobre o temperamento de cada uma. Enquanto Clara se desespera apenas por não ser amparada pelo marido, Vivi faz com que o enfoque recaia sobre si no momento em que percebe que o marido a defendia. É que Vivi agora tem uma superioridade numérica no confronto com a irmã, o que a faz aumentar o drama para vencer a disputa. Vivi não quer apenas equilibrar as coisas, mas prevalecer sobre os demais, mesmo sobre o marido, que é apenas um aliado momentâneo. Se Vivi tenta respeitar o equilíbrio do momento dramático é porque isso é necessário para prevalecer no jogo das aparências.

Todo o capítulo é baseado nesse jogo de aparências, que tem como principais causadores Vivi e Celeu. Clara e Fernando participam desse jogo na medida em que precisam se proteger. Há neles uma passividade que é própria de quem não tem grandes ambições e buscam acabar logo com o conflito do momento para reestabelecer o equilíbrio. Assim, por exemplo, quando Fernando recebe um aumento de ordenado, Celeu se inquieta: "isso de empregado subalterno é um aviltamento, só dos sem habilidade nenhuma. Não sei pra quê se aumenta ordenado de gente assim!" (ANDRDADE, 2015, p. 184). A afirmação de Celeu deixou a todos incomodados, Clara e Quinzinho reagiram, mas Fernando tentou encerrar o assunto: "Ora, pelo amor de Deus, quem sabe se querem fazer uma luta de boxe por minha causa, que bobagem, Clara". Essa passividade, no entanto, não exclui Clara e Fernando do drama, apenas faz com que eles tenham 
papeis diferentes. O dramático se estabelece pelo fato de as vozes estarem em consonância com o problema. É o próprio contraste das vozes que cria essa consonância e faz com que o núcleo dramático se mantenha. Os personagens atraem uns aos outros na medida em que conflitos são gerados.

O ponto de ruptura do núcleo dramático se dá por causa de Dona Eulália. A personagem que menos se adaptou a vida na cidade, por ter ficado sem sua função antiga da fazenda, e que menos participava do jogo de aparências, por se sacrificar em prol da família, foi justamente quem intuiu a solução do drama. Dona Eulália é descrita como a personagem que se preocupa com as coisas práticas, como a saúde da família e a educação das crianças. É a única personagem que não tenta defender o próprio ego. Por isso torna-se quem mais sofre com os conflitos da família. É justamente por estar de fora do jogo que a personagem pode intuir que a solução seria a mudança de toda a família para a fazenda, com exceção de Vivi e Celeu, que eram os principais causadores dos conflitos. Mas uma conclusão assim tão realista não podia chegar à consciência da personagem:

\begin{abstract}
E vinha que Vivi não podia se sentir do que a mãe falara porque se tinha sacrifício, sacrifício não era o de Vivi ainda moça, com marido, com filha, com distração, mas sim dela, a "coitada" que se sacrificava pelo bem de todos, Fernando e Celeu não se davam bem mesmo, Quinzinho que estava muito doente, a própria vida de fazenda sempre fora um sacrifício para Vivi, e ela, coitada, ia se encafuar no sítio pro resto da vida... Ficou com vergonha dessa noção que não era verdade dentro dela. Quis fugir da noção mas esta aguentou firme no lugar porque iam pra fazenda refazer a fortuna que pra quê que estavam trabalhando tanto se não era pra deixar mesmo pra Vivi com Clara e os netos? (ANDRADE, 2015, p. 214).
\end{abstract}

Dona Eulália não compreende a real motivação da decisão de se mudar para a fazenda, que é puramente intuitiva, e tenta explicar a si mesma com falsas motivações a necessidade de se separar de Vivi e Celeu. Esse procedimento se repete em todo o capítulo. Os personagens não conseguem compreender as reais motivações de suas ações e preenchem o vazio com falsas motivações que geralmente são muito convenientes, isto é, estão de acordo com as ambições sem prejudicar a imagem que cada um tem de si mesmo. Mas as ações dos personagens, ainda que bem sucedidas, não traziam a eles satisfação. Ou melhor, poderiam trazer uma satisfação aparente, assim como eram as 
motivações, uma satisfação que era só a de ter vencido uma partida chata contra um adversário difícil: "Todos ali eram profundamente desarticulados, profundamente infelizes, mas a infelicidade que tinham não a percebiam com a consciência e nem mesmo com a sensação, era uma infelicidade muito confundível com a vida e por isso por demais sutil. Sentiam precisão de uma tristeza mais objetiva" (ANDRADE, 2015, p. 182).

Dona Eulália decide ir para a fazenda sem levar Vivi e Celeu e essa decisão rompe o núcleo do drama familiar. A mudança que sofre os personagens após essa separação faz voltar a estrutura própria do romance, gênero que mais faz sentir a ação do tempo.

\begin{abstract}
Vivi estava outra, estava enfim Vivi. Em vintes dias de liberdade da mãe, ela se realizara em seu destino verdadeiro. Poucos minutos depois da partida dos pais, dera a primeira ordem. Não era mais Vivi conseguindo tudo por mil e um subterfúgios, era uma cabeça mandando, era uma forte, uma força completada, sem superstições nem preconceitos. A vida da casa e da família se reorganizou num piscar de olhos (ANRADE, 2015, p. 231).
\end{abstract}

Rompido o drama familiar, rompem-se também as amarras que faziam com que Vivi usasse de subterfúgios para respeitar os limites que o núcleo dramático impunha. Acabado o drama, acabava também a necessidade de manter a unidade por meio de ações que estão em consonância com o problema. Cada personagem passa a poder seguir seu próprio caminho. Mas isso não significa o fim dos conflitos. Significa que a unidade dramática se rompe para que se possa voltar à busca pela totalidade. A unidade dramática pode ser apenas uma totalidade em si mesma, mas não uma totalidade em relação ao mundo. Quinzinho perdeu o medo que Ihe acompanhava na cidade e voltou a ter uma segurança irracional de estar na fazenda que ele sentia ser sua. Eulália readaptou-se rapidamente à sua antiga vida. Clara perdeu grande parte daquela sensualidade que tinha adquirido na cidade, o que causou estranhamento a Fernando: "O resto era espiritualidade, era amor verdadeiro, era dedicação completa ao esposo, ou melhor, à família" (ANDRADE, 2015, p. 238). Acabado o drama, o momento seria do retorno de Chico Antônio que não pôde se completar devido ao fato de o romance não ter sido finalizado. 


\section{Senso comum e cultura de massa}

Esse drama familiar só pode ter um efeito cômico por que o vazio existencial e intelectual dos personagens sofreu grande impacto com os atrativos da vida nova na cidade grande. Não que tivessem alterado sua essência, mas a mudança fez com que o interior dos personagens passasse a se inquietar com as novas possibilidades de vida e as constantes necessidades de adaptação. $O$ fato de não encontrarem em si os recursos necessários para essa adaptação causava-Ihes um sofrimento que se manifestava objetivamente nos conflitos familiares. É que nem mesmo o sofrimento chegava à consciência, tamanho era o vazio existencial dos personagens. Vivi era a única que se adaptou à vida na cidade, mas mesmo ela viu nascer um turbilhão de novas sensações na medida em que os costumes da fazenda eram suplantados pela sensualidade da nova vida. Essa constante necessidade de adaptação fazia com que os integrantes da família adotassem novos hábitos. Nesse sentido, a leitura de jornais e revistas é emblemática e nos revela muito mais do que uma simples forma de distração.

Conforme visto no tópico anterior, a vida nova na cidade distanciou os membros da família e os tornou mais desarticulados e isolados. Ocorre que essa fragmentação tornava necessário algum modo de aproximação, ainda que em outro nível. O modo encontrado, mesmo sem que eles soubessem disso, foi por meio do senso comum que era formado pelas leituras, principalmente do jornal $O$ Estado de São Paulo. No nível da consciência, as leituras eram feitas por divertimento e distração, mas nisso estava oculto a necessidade de enquadramento à nova vida. No entanto, nem sempre o senso comum teve esse sentido deturpado de alienação a uma ideia dominante. No passado, o senso comum era visto como aquilo que estava relacionado às ações práticas e tinham como objetivo o bem da comunidade. O filósofo Hans-Georg Gadamer (1997, p. 72) cita a concepção de senso comum de Shaftesbury: "Para sensus comunnis nós encontramos a tradução 'coração' e a seguinte descrição: 'O sensus comunnis está às voltas com coisas puras que os homens veem diante de si cotidianamente, coisas que mantém unida toda uma sociedade." Esse sentido humanista de senso comum só poderia existir em uma verdadeira comunidade. $\mathrm{Na}$ sociedade moderna, o bem comum deixa de prevalecer e passa-se a priorizar 
o indivíduo. Seu sentido humanista se torna deturpado e o senso comum passa a designar o pensamento não refletido que gira em torno da ideologia dominante. Assim, O Estado de São Paulo tornou-se a principal referência para a família:

\begin{abstract}
Todos liam o mesmo jornal e da mesma maneira. E para todos $O$ Estado de São Paulo era a lei. Um que não concordasse, derramava o pânico na fazendeirada que pensava assim porque O Estado de São Paulo pensava assim. Ficavam irritados, aquele um independente não chocava pela independência, era concebido por uma espécie de grandíssimo tonto, parecidos com esses jornais errados, cheios de letras de todos os tamanhos, atrapalhantes, e não verdadeiros como $O$ Estado de São Paulo. (ANDRADE, 2015, p. 158).
\end{abstract}

A vida em comum, em certa medida permitida pelo ambiente da fazenda, agora só podia ser encontrada na cidade por meio de uma mesma visão de mundo que era formada pela opinião produzida pelo jornal e somente reproduzida pelos membros da família. No nível da consciência, as leituras eram feitas por divertimento e distração, mas nisso estava oculto a necessidade de enquadramento à nova vida. O Estado de São Paulo era o jornal verdadeiro, o produtor da opinião que era correta e não permitia réplicas. Pelo menos era assim que os personagens entendiam a função do jornal. Nesse sentido, é importante notar que o folhetim, assim como os demais gêneros publicados no jornal, não pretendia apenas divertir, mas também era uma fonte de conhecimento:

\footnotetext{
Pela prosa folhetinesca, o homem moderno conquista o saber num modo resfolegante e contraditório (...) O romance, além de sua função lúdica, tem uma função assertiva, seus dados têm total validade e constituem um laço entre os homens mais fundamental que a política (...) 0 proletário, qual pássaro, voa de narrativa em narrativa, nela encontrando apoio e conforto... O romance folhetim fala sempre segundo duas postulações simultâneas: em direção à representação do cotidiano, ao verismo, e em direção ao espetacular, ao excesso. E o verismo implica também o ensinamento. (GILLET apud MEYER, 1996, p. 226).
}

A publicação em partes do folhetim também tinha uma função mercadológica. Trata-se de uma "fragmentação noticiosa que cai como uma luva para as mentalidades fragmentadas, diluídas, difusas, que veem o contexto social, a realidade, sem nenhum nexo, sem nenhum fio ordenado" (MARCONDES apud MEYER, 1996, p. 225). Assim, essa fragmentação, além de manter a fidelidade do público consumidor ansioso pela continuação da história, também permite a identificação desse mesmo público com a estrutura do folhetim. Não é a 
narrativa contada que perde a linearidade e se fragmenta; é a publicação que se torna fragmentada, o que permite ao público um maior envolvimento com a leitura devido aos recursos teatrais, como os ganchos e o suspense. Não se trata, portanto, de uma fragmentação que procura imitar na forma a desarticulação do mundo moderno, mas de um procedimento que visa captar o grande público e mantê-lo fiel. O objetivo é mercadológico, não estético.

Mas o folhetim também divide espaço com outros gêneros dentro do jornal. Todos eles procuram de alguma forma ensinar o público, mas o folhetim o faz indiretamente enquanto outros gêneros o fazem diretamente. Assim, há uma proliferação de gêneros, alguns deles oferecendo dicas diversas sobre coisas práticas: "A ficção ainda encanta seu leitor, mas ela sozinha não é mais suficiente para alimentar sua inteligência, que os acontecimentos de cada dia mantêm acesa" (MEYER, 1996, p. 226). No entanto, esses outros gêneros se aproximam do próprio folhetim e ganham formato de narrativa, considerando uma boa dose de sensacionalismo. Mesmo as notícias mais sérias não escapam desse formato: "Uma informação que apazigua e suscita a curiosidade de um público para quem o 'excesso' visceral do melodrama sempre foi 'natural'” (MEYER, 1996, p. 224 225). Daí a ideia de uma "folhetinização da informação" (GILLET apud MEYER, 1996, p. 224). Essa ideia surgiu primeiramente a propósito dos faits divers, mas o sensacionalismo se prolifera para além deles e alcança outros gêneros do jornal.

Os jornais e revistas eram usados, portanto, para ocupar o espaço que a ociosidade da vida na cidade deixava. Quinzinho "lia todos os jornais com um desinteresse novo, por curiosidade só, pra passar o tempo, coisa que antes não sabia o que era. Dantes, na fazenda, cada noticinha à toa, só vendo como ele se apaixonava!" (ANDRADE, 2015, p. 157) A falta de apuro intelectual dos personagens e o estilo de vida burguês que levavam fazia com que formassem 0 ideal de leitor pretendido pela indústria da cultura de massa. A leitura despretensiosa moldava a opinião do público a uma mesma cosmovisão que via na ideologia dominante a ordem estabelecida que deveria ser protegida. Daí a indignação do senso comum contra aquilo que vai contra essa ordem. Nesse sentido, a opinião contrária ao que diz o veículo de comunicação de massa está no mesmo plano dos marginais que infringem as leis. A opinião contrária é também uma espécie de marginalização, pois ameaça aquilo que se tem como 
correto. Essa cosmovisão atende diretamente aos interesses das classes dominantes, mas chega também às classes menos privilegiadas, inseridas no senso comum do qual a cultura de massa é a principal disseminadora.

É certo que a família das duas irmãs ignora essa questão ideológica e que a vida na cidade e a cultura de massa exercem um efeito destrutivo na desarticulação da família. Os personagens da família nunca chegaram a ser verdadeiramente ricos, apesar de todo dinheiro que se acumulara com a produção de café. O que havia era uma necessidade de ostentação que crescia na medida em que não conseguiam se sentir parte da elite paulistana. Essa discrepância entre o que eles realmente eram e o que gostariam de ser na cidade causa um efeito cômico que se percebe na tentativa de adaptação ao novo ambiente. A família parece ser um meio termo do público consumidor dos jornais e revistas, pois possui a carência cultural das classes menos favorecidas, embora tenha o poder aquisitivo para o consumismo das classes mais elevadas. Os personagens encarnam a figura do novo rico, que é o eixo principal do núcleo dramático e está na base da configuração da unidade em torno do problema. Assim, a importância do jornal se faz notar no romance por evidenciar a influência da cultura de massa em todas as camadas da sociedade.

A configuração própria do folhetim, até então um dos principais representantes dessa cultura, explica essa influência. Essa configuração é reveladora também por conter características de outros gêneros publicados nos jornais e revistas. A pretensão de atingir o público em geral fazia com que se adotassem estratégias para que a leitura fosse interessante para todos. Zola (apud MEYER, 1996, p. 230), a esse respeito, afirma: "É preciso agradar a uma multidão (...) realizando o milagre de contentar todo mundo sem arranhar ninguém". Parte dessas estratégias consistia em ter uma finalidade prática sem deixar de ter seu aspecto lúdico, de modo que pudesse "ser um ensino perpétuo e um divertimento cotidiano". E então cada gênero teria predomínio de um desses aspectos, divertimento ou ensino, mas sem deixar de conter o outro em sua configuração, direta ou indiretamente. No caso do folhetim o ensino aparecia de modo indireto, por meio de inferências do leitor sobre o destino da personagem, destino que revelava a moral vigente na época, principalmente no que diz respeito 
ao comportamento das mulheres. Ao contrário do romance, no folhetim a moral era um a priori, pois era a mesma criada e protegida pelas instituições.

$O$ fato de os personagens de Café justificarem seus atos com falsos pressupostos se dá pela necessidade de não comprometer a moral vigente. As duas irmãs, acomodadas à ordem estabelecida, querem também encontrar um modo de satisfazer os impulsos novos que surgem com a vida na cidade sem ferir a moral. A passividade de Clara torna mais fácil a solução do problema. Para ela, basta transferir a sensualidade em que os impulsos se traduziam para a relação com Fernando. Após uma briga entre a família, Clara vai ao quarto se queixar para Fernando dos exageros de Vivi, mas "Fernando não quis dar razão a Clara e Ihe pediu que não discutisse nunca, nunca mais. Clara ficou calma de repente apoiada na razão do marido. E tiveram uma noite sublime de amor" (ANDRADE, 2015, p. 182). Mas para o temperamento de Vivi a sensualidade não podia ser canalizada apenas na relação com o marido. O conflito que sua sensualidade lhe causa pode ser percebido na festa dada pelo chefe de Celeu em que ela fora o centro das atenções:

Tudo ela podia possuir, timidez, audácia, malicia, bobice, desprezo, sensualidade, mas o que não havia na aparência daquele serzinho gozado eram esses lados água na fervura, virtude normalizada, honradez consciente, ou essa religião antiga, que na alta eles chamavam de 'misticismo' (...) E aliás estava mesmo embebedada pelas atenções, sentindo-se o prêmio da festa. Num momento em que a delícia a perturbava mais, procurou Celeu num vago instinto de proteção (ANDRADE, 2015, p. 193).

Esse conflito com a moral vigente se manifesta de modo diferente, mas existe em todos os personagens. A leitura dos jornais e revistas era uma forma de se enquadrar ao comportamento adequado da sociedade no que diz respeito às coisas práticas do cotidiano, mas também à moral vigente. Se não podia haver completo equilíbrio entre os impulsos e a moral, ao menos o jornal lembrava a necessidade de dissimular a sensualidade para que não se tivesse o mesmo destino da mulher de vida dúbia dos folhetins. 


\title{
DRAMATIC CORE AND COMMON SENSE: A READING OF CAFÉ, BY MÁRIO DE ANDRADE
}

\begin{abstract}
This study will examine the novel Café, of Mário de Andrade, under the formal and ideological perspectives. In the first case will be analyzed the dramatic core that develops in chapter Duas Irmãs, considering that core is inserted in a "dramatic break". This is due to the fact that the main weft of the novel is interrupted for the dramatic core can develop. So, Café includes in its structure characteristics of the novel and drama genres, which shows the scope allowed by the literature. Ideological analysis shows how the press contributes to the diffusion of common sense in order to fill the daily lives of the characters around a dominant ideology. This ideology notes by behavior bourgeois family submits with the city life, influenced particularly by reading newspapers and serials.
\end{abstract}

Key-Words: Mário de Andrade. Dramatic core. Commom sense. Ideology.

\section{Referências}

ANDRADE, Mário de. Café. Editora Nova Fronteira. Rio de Janeiro: 2015.

GADAMER, Hans-Georg. Verdade e método. Tradução: Flávio Paulo Meurer. Editora Vozes. Petrópolis: 1997.

LUKACS, Georg. Teoria do romance. Tradução: José Marcos Mariani de Macedo Editora 34. São Paulo: 2009.

MEYER, Marlyse. Folhetim, Uma história. Cia das letras. São Paulo: 1996.

Data de Submissão: 02/03/17

Data de Aprovação: 06/05/17 